\title{
Cross-cultural pilot study on the relationship between study addiction and narcissism among undergraduate students in Poland and India
}

\begin{abstract}
BACKGROUND
Study addiction has been suggested as a potential early form of work addiction which is recently gaining increasing attention as a potential behavioural addiction. It was suggested that underlying psychological vulnerabilities can be risk factors for study/work addiction. Previous studies indicated that work addiction could be related to narcissistic personality. The aim of this pilot study was to investigate the relationship between study addiction and narcissism in the very distinct cultures of Poland and India.
\end{abstract}

\section{PARTICIPANTS AND PROCEDURE}

In a pen-and-pencil cross-sectional study, the Bergen Study Addiction Scale, Single Item Narcissism Scale, and questions concerning demographics were administered to 1127 undergraduate students in Poland and 292 undergraduate students in India (Karnataka province).
RESULTS

Study addiction was positively related to narcissistic personality among students in Poland, as well as among students in India. This relationship tended to be stronger in the sample from India, which may reflect the cultural differences; however, the difference was not statistically significant.

\section{CONCLUSIONS}

These initial results suggest that study addiction is positively related to narcissism, and potentially to a narcissistic personality disorder. Narcissism is a complex construct which has been gaining increasing attention in recent years. More sophisticated studies on its relationship with study and work addiction, especially in a cross-cultural context, are highly warranted.

\section{KEY WORDS}

cross-cultural; narcissism; narcissistic personality; study addiction; work addiction; workaholism

ORgANIZATION - 1: Institute of Psychology, University of Gdansk, Poland · 2: Karnatak University, Dharwad, India AUthors' CONTRiButions - A: Study design - B: Data collection · C: Statistical analysis - D: Data interpretation .

E: Manuscript preparation - F: Literature search · G: Funds collection

CORRESPONDING AUthor - Paweł Andrzej Atroszko, Ph.D., Institute of Psychology, University of Gdansk, 4 Bażyńskiego Str., 80-309 Gdansk, Poland, e-mail: p.atroszko@ug.edu.pl 


\section{BACKGROUND}

Recently, study addiction has been identified as a potential early form of work addiction (Atroszko, 2015, 2018, 2019a; Atroszko, Andreassen, Griffiths, \& Pallesen, 2015; Griffiths, Demetrovics, \& Atroszko, 2018), which has been recognized as a serious problematic behaviour for decades (Atroszko, 2019b; Atroszko \& Griffiths, 2017). It was conceptualized within contemporary theories of work addiction and it can be defined analogously to a recently proposed general definition of work addiction as "characterized by a compulsion to study and preoccupation with study activities leading to a significant harm and distress of a functionally impairing nature to the individual and/ or other significantly relevant relationships (friends, family). The behaviour is characterized by the loss of control over the studying activity and persists over a significant period of time. This problematic studyrelated behaviour can have varying intensity from mild to severe" (Atroszko, Demetrovics, \& Griffiths, 2019, p. 9). Study addiction was shown to be related to work addiction in longitudinal research (Atroszko, Andreassen, Griffiths, \& Pallesen, 2016a) and showed similar temporal stability to work addiction (Atroszko, Andreassen, Griffiths, \& Pallesen, 2016b). Both addictions show seven core addiction symptoms: salience, mood modification, tolerance, withdrawal, conflict, relapse, and problems (Atroszko et al., 2015). Moreover, both of them are related to higher engagement in studying/working, longer time devoted to studying/ working, key personality traits (higher neuroticism and conscientiousness), lower performance levels, impaired general health, decreased quality of life, poor sleep, and higher perceived stress (Atroszko, 2015; Atroszko et al., 2015; Griffiths et al., 2018). Furthermore, study addiction and work addiction show similar prevalence rates, which are typically around 8-10\% (Atroszko, 2015; Griffiths et al., 2018); however, some studies suggest higher rates in particular populations. For example, the known prevalence rates based on a polythetic cut-off score of the Bergen Work Addiction Scale (which in the absence of the gold standard can be considered the most theoretically sound and empirically valid available cut-off) suggest $6.6 \%$ addicted in Denmark, $8.3 \%$ in a nationally representative sample in Norway, and $16.8 \%$ in Poland (Andreassen et al., 2014; Atroszko, Pallesen, Griffiths, \& Andreassen, 2017; Lichtenstein, Malkenes, Sibbersen, \& Hinze, 2019). The analogous cut-off score based on the Bergen Study Addiction Scale showed that the prevalence rate of study addiction in an online sample in Norway was 9.7\%, and in convenience samples of students in Poland, rates varied from $6.4 \%$ in samples collected during classes at university to $14.2 \%$ in samples collected online (Atroszko, 2015), and $16.0 \%$ among students of music academies (Lawendowski, Bereznowski, Wróbel, Kierzkowski, \& Atroszko, 2019). These differences in prevalence rates may be closely related to cultural factors and their interaction with socioeconomic conditions of particular countries, for example, an interaction of work ethic, consumer values and economic pressures (see Atroszko et al., 2019a).

The results of studies on the differences between study addiction and learning engagement, two constructs that are related but significantly differ in terms of antecedents and consequences, parallel the findings related to work engagement and work addiction (Atroszko, 2018, 2019a; Atroszko et al., 2015; Griffiths et al., 2018). There are different frameworks distinguishing healthy and unhealthy engagement in particular behaviours (e.g., Vallerand, 2015); however, it should be stressed that study addiction fits well into the diagnostic criteria of behavioural addiction. It phenomenologically presents itself as compulsive behaviour, shows a relationship with deteriorated functioning, and it is temporally stable. These are among the key criteria for distinguishing a psychiatric disorder (see Atroszko, 2019a, b; Atroszko \& Griffiths, 2017; Atroszko et al., 2019a; Griffiths et al., 2018). It has been proposed that excessive studying may be a purely obsessive-compulsive disorder (Loscalzo \& Giannini, 2018a, b). However, these suggestions have been thoroughly analysed, and it has been extensively argued that the data seem more congruent with a model in which obsessive-compulsiveness underlies some types of work/study addiction (but not all), and it was tentatively suggested that some forms of obsessive-compulsive personality disorder (OCPD) could be reclassified as work/study addiction (Atroszko, 2018, 2019a,b; Atroszko et al., 2019a). Still, more studies are required to understand the nature, different forms and underlying risk factors of this problematic behaviour.

Narcissism is one of the most frequently investigated personality traits analysed in the context of recent cultural changes caused by globalisation and the popularity of the Internet (see Twenge \& Campbell, 2009). A generational trend of increasing narcissism can be observed in previous decades (Twenge, Konrath, Foster, Keith Campbell, \& Bushman, 2008), and these changes are not limited to Western cultures (Cai, Kwan, \& Sedikides, 2012). Although conceptualizations and structure of narcissism are still discussed (e.g. factors contributing to its heterogeneity, see Back et al., 2013; Miller, Lynam, Hyatt, \& Campbell, 2017), recent models emphasize interpersonal antagonism (Miller et al., 2016) and self-importance (Krizan \& Herlache, 2018) as its core features. Analysing peripheral features of narcissism shows its two different forms: neurotic (anxious, introverted) and agentic (emotionally stable, extraverted), with specific ways of psychosocial functioning and different coping strategies (see Miller et al., 2011).

In this paper, it is suggested that narcissism may be a potential risk factor for study addiction. It was recently argued that work and study addiction may 
be dysfunctional ways of coping with some underlying problems (Atroszko, 2019a, b; Atroszko et al., 2019) similarly to the way other addictions are conceptualized and diagnosed. Previous studies showed an association between work addiction and obsessivecompulsive disorder (OCD), OCPD, depression, anxiety, and ADHD (Andreassen, Griffiths, Sinha, Hetland, \& Pallesen, 2016; Atroszko et al., 2017), which are all positively related to the neurotic aspect of narcissism (Miller et al., 2011). There are also a few studies showing a direct relationship between work addiction and narcissism (Andreassen, Ursin, Eriksen, \& Pallesen, 2012; Clark, Lelchook, \& Taylor, 2010; Golińska, 2008), as well as with achievement-oriented personality traits (Clark, Michel, Zhdanova, Pui, \& Baltes, 2016). Moreover, previous studies (Atroszko, 2015; Atroszko \& Atroszko, 2019) showed a relationship between study addiction and basic features of both agentic and antagonistic narcissism forms: i) the need for achievement, which may be understood as an ego-boosting striving for uniqueness (see Schwartz, 2012; Back et al., 2013), and ii) competitiveness component of Type A personality, which may be understood as an ego-protecting striving for supremacy. Congruently, studies showed a consistent link between study addiction and higher examination stress as well as social anxiety in diverse samples of students (Atroszko, 2015; Atroszko, Wróbel, Bereznowski, \& Lawendowski, 2019b; Lawendowski et al., 2019). Study addiction was conceptualized as an ineffective coping mechanism typical for individuals who are perfectionists, need to demonstrate their competencies as well as who obsessively try to avoid making any mistakes in fear of losing respect and admiration of other people, and the initial data support such assumptions (see Atroszko, 2015, 2018, 2019a). What should be emphasised is that a preliminary study showed that competitiveness related to higher cardiovascular risk is characteristic for study addiction but not for healthy study engagement (Atroszko \& Atroszko, 2019).

On the basis of these results, it can be assumed that narcissistic tendencies are an independent risk factor for study and work addiction. So far, there are no studies on the association between study addiction and narcissism, and the aim of this study was to provide initial data on this issue. Moreover, it was recently argued that macro-level factors, such as the culture of the country or its socioeconomic conditions, may have a significant and substantial effect on work and study addiction, and at the same time, these are the least studied factors (Atroszko et al., 2019a). Therefore, it is assumed that the highly patriarchal culture of India, in comparison to the less patriarchal culture of Poland (see Global Gender Gap Index, World Economic Forum, 2015), will have an effect on the strength of the relationship between narcissism and study addiction, and that in India there will be a stronger association between these variables among men than women. It is based on the supposition that males who are narcissistic will want to demonstrate their value to a larger extent than females through more traditional agency-based activities, such as achievements in study and work.

\section{PARTICIPANTS AND PROCEDURE}

\section{PARTICIPANTS}

The Polish sample comprised 1182 undergraduate students. Due to missing data on relevant variables, 55 participants were eliminated from the analyses. When data were missing at random and only a very small portion of data were missing (less than $2 \%$ overall), missing data were imputed using Missing Values Analysis within SPSS 25.0. This algorithm provides unbiased parameter estimates and improves the statistical power of analyses (Enders, 2001). The final sample therefore comprised 590 (52.8\%) females, $527(46.8 \%)$ males, and $10(0.9 \%)$ respondents who did not report gender, with a mean age of 20.34 years $(S D=1.69)$. The individuals were studying at universities in Gdansk: the University of Gdansk, Gdansk Technological University, and Gdansk University of Sport and Recreation. Students were affiliated with different faculties, courses of study and years of study.

The Indian sample was gathered between September and December 2018, and it included 292 students of diverse faculties, courses, modes, and years of studies at Karnatak University in Karnataka province in India. The sample comprised 195 (66.8\%) women and 97 (33.2\%) men, with a mean age of 22.26 years $(S D=1.72)$.

\section{MEASURES}

Study addiction. Study addiction was measured with the Bergen Study Addiction Scale (BStAS; Atroszko, Andreassen, Griffiths, \& Pallesen, 2015). It is a valid and reliable tool based on the Bergen Work Addiction Scale (BWAS; Andreassen et al., 2012). The BStAS is composed of seven items that pertain to experiences during the past 12 months. A sample item is: "How often during the last year have you studied in order to reduce feelings of guilt, anxiety, helplessness and depression?". The Likert-type response scale ranged from 1 (never) to 5 (always). The scale has demonstrated good construct validity and reliability in previous studies (Atroszko, 2015; Atroszko \& Atroszko, 2019; Atroszko et al., 2015, 2016a, b; Atroszko et al., 2019b; Lawendowski et al., 2019). In the present study, single-factor structure was confirmed in the Polish sample (MLR estimator, $\chi^{2}(14)=90.19$, $p<.001$, RMSEA $=.070,90 \%$ CI RMSEA $=.056-.084$, $\mathrm{CFI}=.945$, SRMR $=.031)$ as well as in Indian sample (MLR estimator, error terms of items 1 and 2 cor-
Study addiction and narcissism in Poland and India 
Paweł Andrzej Atroszko, Artur Sawicki, Shanmukh V. Kamble related, $\chi^{2}(13)=23.35, p=.038, \mathrm{RMSEA}=.052,90 \%$ CI RMSEA $=.012-.086$, CFI $=.927$, SRMR $=.046$ ). For a discussion on the rationale for correlating error terms of items 1 and 2, see Atroszko (2018). Cronbach's $\alpha$ for BStAS were .77 in the Polish sample and .63 in the Indian sample. The difference in reliability is probably due to the same reasons the error terms needed to be correlated in the Indian sample, that is that these items in the Indian sample measure to a somewhat larger degree the components of study engagement and not study addiction per se.

Narcissism. Narcissism was measured with the Single-Item Narcissism Scale (SINS; Konrath, Meier, \& Bushman, 2014). It is a valid and reliable tool, measuring global narcissism level with the following item: "To what extent do you agree with this statement: 'I am a narcissist' (Note: The word 'narcissist' means egotistical, self-focused, and vain)". In this study we used a 9-point Likert-type response scale, ranging from 1 (no) to 9 (yes). The Polish version of the scale showed good validity in a previous study (Atroszko et al., 2018).

Learning engagement. Learning engagement was measured with Single-Item Self-Report Measure of Learning Engagement (Atroszko, 2014; Łukowicz et al., 2017). It is a valid and reliable tool, measuring learning engagement with the following item: "How engaged in learning are you?". In this study we used a 7-point Likert-type response scale, ranging from 1 (I am not at all engaged) to 7 (I am completely engaged). The Polish version of the scale showed good validity in the previous research (Atroszko, 2015; Atroszko \& Atroszko, 2019; Atroszko et al., 2015; Atroszko et al., 2019b; Lawendowski et al., 2019).

\section{PROCEDURE}

Convenience sampling was used. Those who were willing to participate (more than 95\%) completed questionnaires anonymously during their regular classes.
No monetary rewards were provided as an incentive to complete the survey.

\section{STATISTICAL ANALYSES}

Missing data (less than 1.5\%) were imputed using the expectation maximization (EM) algorithm. In both samples, hierarchical multiple regression analyses were performed, in which study addiction was the dependent variable, and gender and age were entered as independent variables in the first step, learning engagement was entered in the second step, narcissism was entered in the third step, and the interaction term of narcissism and gender was entered in the fourth step. A bootstrap method with $95 \%$ confidence intervals and 10000 bootstrap samples was used for investigating moderation. All tests were two-tailed, and the significance level was set to $\alpha=.05$. For all linear regression analyses, preliminary analyses were conducted to ensure no violation of the assumptions of normality, linearity, multicollinearity, and homoscedasticity. All analyses were conducted using IBM SPSS 25, and the PROCESS 3.0 macro was used for moderation analysis (Hayes, 2017).

\section{RESULTS}

\section{DESCRIPTIVE STATISTICS}

Table 1 presents mean scores and standard deviations for all the study variables as well as their interrelationships. Narcissism was positively related to study addiction both in Poland and India. However, learning engagement was negatively related to narcissism in Poland and positively in India. Also, the correlation between learning engagement and study addiction was significantly lower in India than in Poland, $z=3.97, p<.001$

Table 1

Mean scores and standard deviations, percentages, and correlations between study variables

\begin{tabular}{|c|c|c|c|c|c|c|c|c|}
\hline & Variable & $\begin{array}{c}M(S D) / \% \\
\text { Polish sample }\end{array}$ & $\begin{array}{c}M(S D) / \% \\
\text { Indian sample }\end{array}$ & 1. & 2. & 3. & 4. & 5. \\
\hline 1. & Gender ${ }^{a, b}$ & $46.8 \%$ males & $33.2 \%$ males & & -.03 & $-.17^{* *}$ & $.20^{* *}$ & $-.13^{* *}$ \\
\hline 2. & Age & $20.34(1.69)$ & $22.26(1.72)$ & $.23^{* *}$ & & $-.11^{* *}$ & .00 & $.07^{*}$ \\
\hline 3. & Learning engagement & $4.75(1.23)$ & $4.66(1.45)$ & .06 & .07 & & $-.08^{*}$ & $.35^{* *}$ \\
\hline 4. & Narcissism & $3.81(2.19)$ & $4.24(2.65)$ & .02 & $.12^{*}$ & $.18^{* *}$ & & $.05^{\mathrm{c}}$ \\
\hline 5. & Study addiction & $2.40(0.78)$ & $3.02(0.68)$ & -.02 & .00 & $.11^{\mathrm{d}}$ & $.18^{* *}$ & \\
\hline
\end{tabular}




\section{REGRESSION ANALYSES}

In the Polish sample independent variables entered in the first step explained $2.0 \%$ of variance, $F(2,1086)=11.18, p<.001$. Learning engagement explained an additional $11.5 \%$ of variance, $F(1,1085)=144.72, p<.001$. Narcissism, entered in the third step, explained an additional $0.9 \%$ of variance, $F(1,1084)=11.35, p=.001$. The interaction between gender and narcissism did not explain any additional variance (see Figure 1), $F(1,1083)=0.02, p=.898$. In total, independent variables explained a total $14.4 \%$ of study addiction variance, $F(5,1083)=36.57, p<.001$. Gender, age, and narcissism were significant predictors of study addiction in the full model (see Table 2).

The interaction plot is presented in Figure 1. The conditional effect of the focal predictor (narcissism) at benchmark values of the moderator variable (gender) showed that there was a positive relationship be-

Table 2

Hierarchical multiple regression analyses, in which study addiction was the dependent variable, and gender, age, narcissism, and interaction between gender and narcissism were independent variables (unstandardized regression coefficients are reported)

\begin{tabular}{|c|c|c|c|}
\hline \multirow[t]{2}{*}{ Step } & \multirow[t]{2}{*}{ Variable } & $\begin{array}{l}\text { Polish } \\
\text { sample }\end{array}$ & $\begin{array}{l}\text { Indian } \\
\text { sample }\end{array}$ \\
\hline & & $B$ & $B$ \\
\hline \multirow[t]{2}{*}{1} & Gender ${ }^{\mathrm{a}}$ & $-.19^{* *}$ & -.03 \\
\hline & Age & $.03^{*}$ & .00 \\
\hline \multirow[t]{3}{*}{2} & Gender $^{\mathrm{a}}$ & $-.10^{*}$ & -.03 \\
\hline & Age & $.05^{* *}$ & .00 \\
\hline & $\begin{array}{l}\text { Study } \\
\text { engagement }\end{array}$ & $.22^{* *}$ & $.05^{\mathrm{b}}$ \\
\hline \multirow[t]{4}{*}{3} & Gender ${ }^{\mathrm{a}}$ & $-.13^{* *}$ & -.03 \\
\hline & Age & $.05^{* *}$ & -.01 \\
\hline & $\begin{array}{l}\text { Study } \\
\text { engagement }\end{array}$ & $.22 * *$ & .04 \\
\hline & Narcissism & $.04^{* *}$ & $.04^{* *}$ \\
\hline \multirow[t]{5}{*}{4} & Gender $^{a}$ & $-.14^{* *}$ & -.23 \\
\hline & Age & $.05^{* *}$ & -.01 \\
\hline & $\begin{array}{l}\text { Study } \\
\text { engagement }\end{array}$ & $.22 * *$ & .04 \\
\hline & Narcissism & $.03^{*}$ & .03 \\
\hline & $\begin{array}{l}\text { Gender* } \\
\text { narcissism }\end{array}$ & .00 & .05 \\
\hline
\end{tabular}

Note. ${ }^{\mathrm{a}} 0=$ women, $1=$ men; ${ }^{\mathrm{b}} p=.055$, interpreted as significant given two-tailed test and in accordance with the direction of the hypothesis. ${ }^{*} p<.05,{ }^{* *} p<.01$. tween narcissism and study addiction among women $(B=.03, p=.023,95 \% \mathrm{CI}[.01, .06])$, as well as among men $(B=.04, p=.013,95 \%$ CI $[.01, .06])$.

In the Indian sample independent variables entered in the first step did not explain any variance of study addiction, $F(2,289)=0.04, p=.960$. Learning engagement explained an additional $1.3 \%$ of variance, $F(1,288)=3.70, p=.055$. Narcissism, entered in the third step, explained an additional $2.8 \%$ of variance, $F(1,287)=8.38, p=.004$. The interaction between gender and narcissism explained an additional $0.7 \%$ of variance (see Figure 2), $F(1,286)=2.21, p=.138$. In total, independent variables explained a total $4.8 \%$ of study addiction variance, $F(4,287)=3.06, p=.017$. Narcissism was the only significant predictor of study addiction (see Table 2).

The interaction plot is presented in Figure 2. The conditional effect of the focal predictor (narcissism) at benchmark values of the moderator variable (gender) showed that there was no significant relationship between narcissism and study addiction among women $(B=.03, p=.137,95 \%$ CI $[-.01, .07])$ and that there was a positive relationship between those variables among men $(B=.08, p=.004,95 \%$ CI $[.02, .13])$.

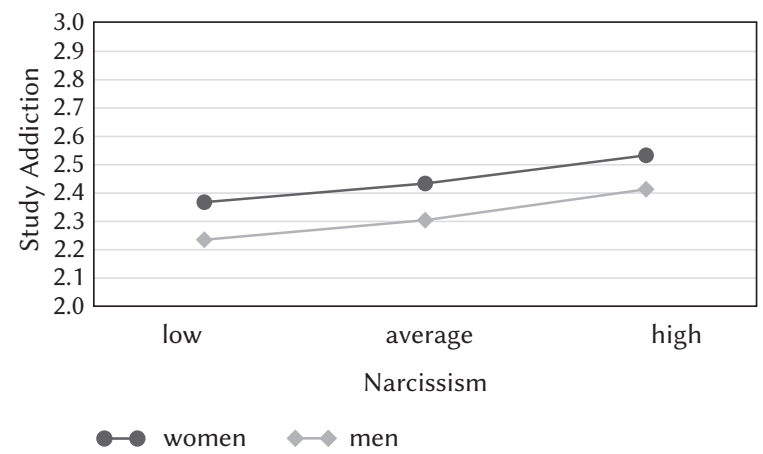

Figure 1. Relationship between narcissism and study addiction among male and female undergraduate students in Poland (controlled for age and learning engagement).

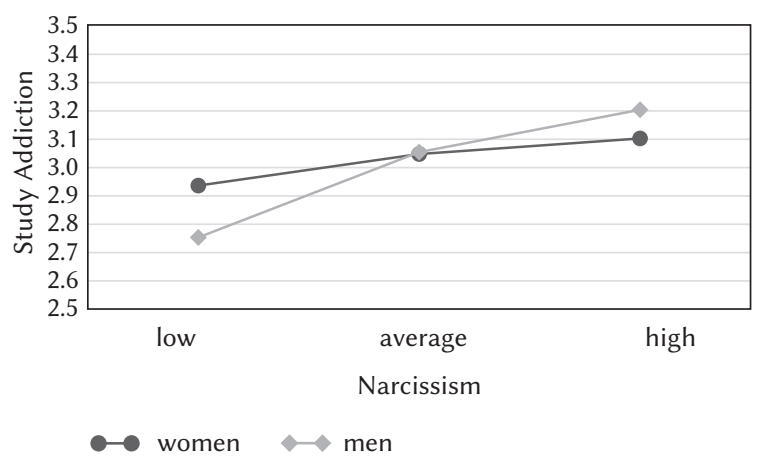

Figure 2. Relationship between narcissism and study addiction among male and female undergraduate students in India (controlled for age and learning engagement).
Study addiction and narcissism in Poland and India 


\section{DISCUSSION}

The main hypothesis was confirmed: study addiction and narcissism were positively related in both samples. It is congruent with previous studies on the relationship between work addiction and narcissism (Andreassen et al., 2012; Clark et al., 2010; Golińska, 2008). Thus far, the focus in the research on work and study addiction has been on their obsessive-compulsive components or underlying mechanisms. How-
Paweł Andrzej Atroszko, Artur Sawicki, Shanmukh V. Kamble ever, this study suggests that to some extent study/ work addicts may be driven by narcissistic motivations and perhaps impulsivity. Impulsivity has been associated before with ADHD and addiction (Urcelay \& Dalley, 2011), and ADHD showed clear relationships with work addiction (Andreassen et al., 2016; Atroszko et al., 2017). Also, impulsivity and compulsivity are correlated (Chamberlain, Stochl, Redden, \& Grant, 2018). It is also possible that different types of study/work addicts may be distinguished on the basis of their underlying vulnerabilities and regulatory mechanisms (see Atroszko, 2019a). This is congruent with previous clinical observations (Robinson, 2014), as well as the findings from crosssectional studies relating work addiction to OCD, OCPD, depression, anxiety, and ADHD (Andreassen et al., 2016; Atroszko et al., 2017). All these are also positively related to the neurotic aspect of narcissism (Miller et al., 2011). The current and previous findings support the notion that work and study addiction may be dysfunctional ways of coping with some underlying problems (Atroszko, 2019a, b; Atroszko et al., 2019a), similarly to the way other addictions are conceptualized and diagnosed. Based on these results, it is also recommended to investigate a potential interaction between obsessive-compulsive traits, ADHD characteristics and narcissistic tendencies, beyond their contribution as independent risk factors in explaining study and work addiction. Moreover, motivations for learning should be investigated in order to unravel to what extent study addicts are driven by personal-focus values, and to what extent they are motivated by social focus values. This can be done within the narcissism-related area of research which distinguishes between agentic narcissism and communal narcissism (Gebauer, Sedikides, Verplanken, \& Maio, 2012). Moreover, differentiation of self-focus achievement orientation and other focus orientation among study addicts could shed more light on the nuanced motivations behind their unduly strong engagement in studying.

The correlation between gender and study addiction was very close to zero in India, which is incongruent with all of the previous studies in Poland and Norway (Andreassen et al., 2013; Atroszko, 2015; Atroszko et al., 2016a, b; Atroszko \& Atroszko, 2019; Lawendowski et al., 2019). Also, the relationship of learning engagement with study addiction was sig- nificantly weaker in India than in Poland. Moreover, learning engagement was related negatively to narcissism in Poland but positively in India. The results of moderation analyses suggest a potential effect of interaction between gender and narcissism in India but not in Poland. Several potential factors may explain these different patterns of relationships between study-related variables, gender and narcissism. Firstly, Indian culture is considered more masculine than Polish (see Global Gender Gap Index, World Economic Forum, 2015); therefore, agentic achievements are more often socially prescribed to men. This may be a good premise to understand some forms of study addiction as a result of societal pressure on agency (related to high socioeconomic position), with no consideration for communality (related to good relations with others). Secondly, the emphasis laid on obtaining a good education in India may be currently stronger than in Western countries as reflected by the formal education development indicators (Lee \& Lee, 2016). These results point to an important area of research that clearly requires further studies. There is still limited evidence on how the broader cultural factors affect psychological processes related to schooling. However, the existing studies suggest that the cultural dimensions of individualism/collectivism and power distance may influence functioning in school (Cortina, Arel, \& Smith-Darden, 2017), and potentially later during studies. A cross-cultural investigation of study addiction in Asian cultures should arguably include the role of such factors as filial piety, found to be related to academic performance in previous studies (Yeh \& Bedford, 2003). Since in Asian countries study and work tend to be strongly driven by collectivistic values, communal aspects of narcissism should be explored in relation to study addiction.

\section{STRENGTHS AND LIMITATIONS}

To the authors' knowledge this is the first study to investigate cross-culturally the relationship between study addiction and narcissism. Relatively large samples were used, providing sufficient statistical power to detect even small effects. Valid and reliable measures were used, and proper analytical procedures were conducted. However, this is a pilot study, which needs to be replicated and extended; therefore, there are some limitations to it. While the single-item measures were carefully selected and validated in the previous studies, and they show test-retest reliability comparable to or only slightly lower than their multiitem counterparts, the limitations of such measures need to be taken into account (e.g. limited precision). Although the Polish sample may be considered as large and heterogeneous in terms of universities and courses, the Indian sample is not, and it is still, to some extent, statistically underpowered. Future stud- 
ies should examine larger samples of students from different universities and different provinces. Also, having such samples will allow for adequate testing of measurement invariance of the BStAS and other relevant measures. This is a necessary condition for any meaningful cross-cultural comparisons. Moreover, the cross-sectional design of the study does not allow for causal inferences.

\section{CONCLUSIONS AND FUTURE RESEARCH DIRECTIONS}

This study provides initial data on the relationship between narcissism and study addiction, setting a framework for further, extended studies in this area. Narcissism, as a complex construct, needs to be measured more thoroughly in the subsequent studies in order to identify which of its features (neuroticism, antagonism, and extraversion) are related to study addiction. In order to make some inferences about the universal characteristics of study addiction, individuals from more cultures should be examined. The results suggest potential culture and gender moderation effects, but larger samples are required to detect them. Whereas this is a pilot study, one of its aims is to draw the attention of experts from diverse fields, including personality psychologists and cross-cultural researchers, to a fairly prevalent problem of high significance to the wider public, potentially existing in most if not all countries with modern education systems, and whose manifestation is likely affected by cross-cultural differences.

\section{RefERENCES}

Andreassen, C. S., Griffiths, M. D., Gjertsen, S. R., Krossbakken, E., Kvam, S., \& Pallesen, S. (2013). The relationships between behavioral addictions and the five-factor model of personality. Journal of Behavioral Addictions, 2, 90-99. https://doi.org/ 10.1556/JBA.2.2013.003

Andreassen, C. S., Griffiths, M. D., Hetland, J., Kravina, L., Jensen, F., \& Pallesen, S. (2014). The prevalence of workaholism: A survey study in a nationally representative sample of Norwegian employees. PLoS One, 9, e102446. https://doi.org/10.1371/journal.pone.0102446

Andreassen, C. S., Griffiths, M. D., Sinha, R., Hetland, J., \& Pallesen, S. (2016). The relationships between workaholism and symptoms of psychiatric disorders: a large-scale cross-sectional study. PLoS One, 11, e0152978. https://doi.org/10.1371/ journal.pone. 0152978

Andreassen, C. S., Ursin, H., Eriksen, H. R., \& Pallesen, S. (2012). The relationship of narcissism with workaholism, work engagement, and professional posi- tion. Social Behavior and Personality: An International Journal, 40, 881-890. https://doi.org/10.2224/ sbp.2012.40.6.881

Atroszko, P. (2014). Developing brief scales for educational research: Reliability of single-item self-report measures of learning engagement and exam stress. In M. McGreevy \& R. Rita (Eds.), Proceedings of the 1st Biannual CER Comparative European Research Conference (pp. 172-175). London: Sciemcee Publishing. Retrieved from http://www.sciemcee.org/library/proceedings/cer/cer2014_proceedings01.pdf\#page $=172$

Atroszko, P. A. (2015). The structure of study addiction: Selected risk factors and the relationship with stress, stress coping and psychosocial functioning (unpublished doctoral thesis). Gdansk: University of Gdansk.

Atroszko, P. A. (2018). Commentary on: The Bergen Study Addiction Scale: psychometric properties of the Italian version. A pilot study. Theoretical and methodological issues in the research on study addiction with relevance to the debate on conceptualising behavioural addictions. Psychiatria i Psychologia Kliniczna, 18, 276-282. https://doi. org/10.15557/PiPK.2018.0034

Atroszko, P. A. (2019a). Response to: Loscalzo and Giannini (2018). A boon of incoherence: insights on the relationship between study/work addiction and obsessive-compulsive personality disorder. Psychiatria i Psychologia Kliniczna, 19, 237-243. https://doi.org/10.15557/PiPK.2019.0025

Atroszko, P. A. (2019b). Work addiction as a behavioural addiction: Towards a valid identification of problematic behaviour. Australian \& New Zealand Journal of Psychiatry, 53, 284-285. https://doi. org/10.1177/0004867419828496

Atroszko, P. A., Andreassen, C. S., Griffiths, M. D., \& Pallesen, S. (2015). Study addiction - a new area of psychological study: Conceptualization, assessment, and preliminary empirical findings. Journal of Behavioral Addictions, 4, 75-84. https://doi. org/10.1556/2006.4.2015.007

Atroszko, P. A., Andreassen, C. S., Griffiths, M. D., \& Pallesen, S. (2016a). The relationship between study addiction and work addiction: A cross-cultural longitudinal study. Journal of Behavioral Addictions, 5, 708-714. https://doi.org/10.1556/2006.5.2016.076

Atroszko, P. A., Andreassen, C. S., Griffiths, M. D., \& Pallesen, S. (2016b). Study addiction: A crosscultural longitudinal study examining temporal stability and predictors of its changes. Journal of Behavioral Addictions, 5, 357-362. https://doi. org/10.1556/2006.5.2016.024

Atroszko, P. A., \& Atroszko, B. (2019). Type A personality competitiveness component linked to increased cardiovascular risk is positively related to study addiction but not to study engagement. Current Science [in press].
Study addiction and narcissism in Poland and India 
Atroszko, P. A., Balcerowska, J. M., Bereznowski, P., Biernatowska, A., Pallesen, S., \& Andreassen, C. S. (2018). Facebook addiction among Polish undergraduate students: Validity of measurement and relationship with personality and well-being. Computers in Human Behavior, 85, 329-338. https:// doi.org/10.1016/j.chb.2018.04.001

Atroszko, P. A., Demetrovics, Z., \& Griffiths, M. D. (2019a). Beyond the myths about work addiction: Toward a consensus on definition and trajectories
Paweł Andrzej Atroszko, Artur Sawicki, Shanmukh V. Kamble for future studies on problematic overworking: A response to the commentaries on: Ten myths about work addiction (Griffiths et al., 2018). Journal of Behavioral Addictions, 8, 7-15. https://doi. org/10.1556/2006.8.2019.11

Atroszko, P. A., \& Griffiths, M. D. (2017). Work addiction is not new to the psychological literature and has evolved over time. Global Journal of Addiction \& Rehabilitation Medicine, 3, 1-2. https:// doi.org/10.19080/GJARM.2017.03.555612

Atroszko, P. A., Pallesen, S., Griffiths, M. D., \& Andreassen, C. S. (2017). Work addiction in Poland: adaptation of the Bergen Work Addiction Scale and relationship with psychopathology. Health Psychology Report, 5, 345-355. https://doi.org/10.5114/ hpr.2017.68759

Atroszko, P. A., Wróbel, W. K., Bereznowski, P., \& Lawendowski, R. (2019b). The relationship between study addiction and examination stress among students of music academies. Roczniki Psychologiczne [in press].

Back, M. D., Küfner, A. C., Dufner, M., Gerlach, T. M., Rauthmann, J. F., \& Denissen, J. J. (2013). Narcissistic admiration and rivalry: Disentangling the bright and dark sides of narcissism. Journal of Personality and Social Psychology, 105, 1013-1037. https://doi.org/10.1037/a0034431

Cai, H., Kwan, V. S., \& Sedikides, C. (2012). A sociocultural approach to narcissism: The case of modern China. European Journal of Personality, 26, 529-535. https://doi.org/10.1002/per.852

Chamberlain, S. R., Stochl, J., Redden, S. A., \& Grant, J. E. (2018). Latent traits of impulsivity and compulsivity: toward dimensional psychiatry. Psychological Medicine, 48, 810-821. https://doi.org/10.1017/ S0033291717002185

Clark, M. A., Lelchook, A. M., \& Taylor, M. L. (2010). Beyond the Big Five: How narcissism, perfectionism, and dispositional affect relate to workaholism. Personality and Individual Differences, 48, 786-791. https://doi.org/10.1016/j.paid.2010.01.013

Clark, M. A., Michel, J. S., Zhdanova, L., Pui, S. Y., \& Baltes, B. B. (2016). All work and no play? A meta-analytic examination of the correlates and outcomes of workaholism. Journal of Management, 42, 18361873. https://doi.org/10.1177/0149206314522301

Cortina, K. S., Arel, S., \& Smith-Darden, J. P. (2017). School belonging in different cultures: The effects of individualism and power distance. Frontiers in Education, 2, 56. https://doi.org/10.3389/feduc.2017.00056

Enders, C. K. (2001). A primer on maximum likelihood algorithms available for use with missing data. Structural Equation Modeling, 8, 128-141. https:// doi.org/10.1207/S15328007SEM0801_7

Gebauer, J. E., Sedikides, C., Verplanken, B., \& Maio, G. R. (2012). Communal narcissism. Journal of Personality and Social Psychology, 103, 854-878. https://doi. org/10.1037/a0029629

Golińska, L. (2008). Pracoholizm: uzależnienie czy pasja. Warszawa: Centrum Doradztwa i Informacji Difin.

Griffiths, M. D., Demetrovics, Z., \& Atroszko, P. A. (2018). Ten myths about work addiction. Journal of Behavioral Addictions, 7, 845-857. https://doi. org/10.1556/2006.7.2018.05

Hayes, A. F. (2017). Introduction to mediation, moderation, and conditional process analysis: A regression-based approach. New York, NY: Guilford Publications.

Konrath, S., Meier, B. P., \& Bushman, B. J. (2014). Development and validation of the single item narcissism scale (SINS). PLoS One, 9, e103469. https:// doi.org/10.1371/journal.pone.0103469

Krizan, Z., \& Herlache, A. D. (2018). The narcissism spectrum model: A synthetic view of narcissistic personality. Personality and Social Psychology Review, 22, 3-31. https://doi.org/10.1177/1088868316 685018

Lawendowski, R., Bereznowski, P., Wróbel,W. K., Kierzkowski, M., \& Atroszko, P. A. (2019). Study addiction among musicians: Measurement, and relationship with personality, social anxiety, performance and psychosocial functioning. Musicae Scientiae. https://doi.org/10.1177/1029864918822138

Lee, J. W., \& Lee, H. (2016). Human capital in the long run. Journal of Development Economics, 122, 147169. https://doi.org/10.1016/j.jdeveco.2016.05.006

Lichtenstein, M. B., Malkenes, M., Sibbersen, C., \& Hinze, C. J. (2019). Work addiction is associated with increased stress and reduced quality of life: Validation of the Bergen Work Addiction Scale in Danish. Scandinavian Journal of Psychology, 60, 145-151. https://doi.org/10.1111/sjop. 12506

Loscalzo, Y., \& Giannini, M. (2018a). The Bergen Study Addiction Scale: psychometric properties of the Italian version. A pilot study. Psychiatria i Psychologia Kliniczna, 18, 271-275. https://doi.org/10.15557/ PiPK.2018.0033

Loscalzo, Y., \& Giannini, M. (2018b). Response to: Theoretical and methodological issues in the research on study addiction with relevance to the debate on conceptualising behavioural addictions: Atroszko (2018). Psychiatria i Psychologia Kliniczna, 18, 426430. https://doi.org/10.15557/PiPK.2018.0051

Łukowicz, P., Choynowska, A., Świątkowska, A. M., Bereznowski, P., Wróbel, W. K., \& Atroszko, P. A. (2017). Validity of single-item self-report measure 
of learning engagement. In J. Nyćkowiak \& J. Leśny (Eds.), Badania i Rozwój Młodych Naukowców w Polsce - Nauki humanistyczne i społeczne. Część IV [Research and Development of Young Scientists in Poland - Humanities and social sciences. Part IV] (pp. 41-49). Poznań: Młodzi Naukowcy. Retrieved from http://experior.ug.edu.pl/ wp-content/uploads/Validity-of-single-item-selfreport-measure-of-learning-engagement.pdf

Miller, J. D., Hoffman, B. J., Gaughan, E. T., Gentile, B., Maples, J., \& Keith Campbell, W. (2011). Grandiose and vulnerable narcissism: A nomological network analysis. Journal of Personality, 79, 1013-1042. https://doi.org/10.1111/j.1467-6494.2010.00711.x

Miller, J. D., Lynam, D. R., Hyatt, C. S., \& Campbell, W. K. (2017). Controversies in narcissism. Annual Review of Clinical Psychology, 13, 291-315. https:// doi.org/10.1146/annurev-clinpsy-032816-045244

Miller, J. D., Lynam, D. R., McCain, J. L., Few, L. R., Crego, C., Widiger, T. A., \& Campbell, W. K. (2016). Thinking structurally about narcissism: An examination of the Five-Factor Narcissism Inventory and its components. Journal of Personality Disorders, 30, 1-18. https://doi.org/10.1521/pedi_2015_29_177

Robinson, B. E. (2014). Chained to the desk: A guidebook for workaholics, their partners and children, and the clinicians who treat them. New York: NYU Press.

Schwartz, S. H. (2012). An overview of the Schwartz theory of basic values. Online Readings in Psychology and Culture, 2, 11. https://doi.org/10.9707/23070919.1116

Twenge, J. M., \& Campbell, W. K. (2009). The narcissism epidemic: Living in the age of entitlement. New York, NY: Free Press.

Twenge, J. M., Konrath, S., Foster, J. D., Keith Campbell, W., \& Bushman, B. J. (2008). Egos inflating over time: A cross-temporal meta-analysis of the Narcissistic Personality Inventory. Journal of Personality, 76, 875-902. https://doi.org/10.1111/j.14676494.2008.00507.x

Urcelay, G. P., \& Dalley, J. W. (2011). Linking ADHD, impulsivity, and drug abuse: a neuropsychological perspective. In C. Stanford \& R. Tannock (Eds.), Behavioral neuroscience of attention deficit hyperactivity disorder and its treatment (pp. 173-197). Berlin, Heidelberg: Springer.

Vallerand, R. J. (2015). The psychology of passion: A dualistic model. New York, NY: Oxford University Press.

World Economic Forum (2015). The global gender gap report. Retrieved from http://reports.weforum.org/ global-gender-gap-report-2015/rankings

Yeh, K., \& Bedford, O. (2003). A test of the dual filial piety model. Asian Journal of Social Psychology, 6, 215-228. https://doi.org/10.1046/j.1467-839X.2003. 00122.x 